\title{
Increased B cell activation is present in JAK2V617F-mutated, CALR-mutated and triple-negative essential thrombocythemia
}

\author{
Ken-Hong Lim ${ }^{1,2,3,4}$, Caleb Gon-Shen Chen ${ }^{2,3,4,5}$, Yu-Cheng Chang ${ }^{2,3,4}$, Yi-Hao \\ Chiang ${ }^{2,3}$, Chen-Wei Kao ${ }^{3}$, Wei-Ting Wang ${ }^{3}$, Chiao-Yi Chang ${ }^{3}$, Ling Huang ${ }^{3}$, Ching- \\ Sung Lin ${ }^{3}$, Chun-Chia Cheng ${ }^{3}$, Hung-I Cheng ${ }^{6}$, Nai-Wen Su${ }^{2,3,4}$, Johnson Lin ${ }^{2}$, Yi- \\ Fang Chang ${ }^{2,3,4}$, Ming-Chih Chang ${ }^{2,3,4}$, Ruey-Kuen Hsieh ${ }^{2,3}$, Huan-Chau Lin ${ }^{2,3}$ and \\ Yuan-Yeh Kuo ${ }^{1}$ \\ ${ }^{1}$ Graduate Institute of Oncology, National Taiwan University College of Medicine, Taipei, Taiwan \\ 2 Department of Internal Medicine, Division of Hematology and Oncology, MacKay Memorial Hospital, Taipei, Taiwan \\ ${ }^{3}$ Department of Medical Research, Laboratory of Good Clinical Research Center, MacKay Memorial Hospital, Tamsui District, \\ New Taipei City, Taiwan \\ ${ }^{4}$ Department of Medicine, MacKay Medical College, New Taipei City, Taiwan \\ ${ }^{5}$ Institute of Molecular and Cellular Biology, National Tsing-Hua University, Hsinchu, Taiwan \\ ${ }^{6}$ Department of Internal Medicine, Division of Hematology and Oncology, MacKay Memorial Hospital, Hsinchu, Taiwan \\ Correspondence to: Ken-Hong Lim, email: khlim@mmh.org.tw
}

Huan-Chau Lin, email: hcanduhmmh@gmail.com

Yuan-Yeh Kuo, email: yykuo@ntu.edu.tw

Keywords: B cell, CALR, essential thrombocythemia, immune

Received: January 06, $2017 \quad$ Accepted: February 28, $2017 \quad$ Published: March 18, 2017

Copyright: Lim et al. This is an open-access article distributed under the terms of the Creative Commons Attribution License (CC-BY), which permits unrestricted use, distribution, and reproduction in any medium, provided the original author and source are credited.

\section{ABSTRACT}

Essential thrombocythemia (ET) is a BCL-ABL1-negative myeloproliferative neoplasm. We have reported that increased activated $B$ cells can facilitate platelet production mediated by cytokines regardless JAK2 mutational status in ET. Recently, calreticulin (CALR) mutations were discovered in 30\% JAK2/MPL-unmutated ET and primary myelofibrosis. Here we sought to screen for CALR mutations and to evaluate B cell immune profiles in a cohort of adult Taiwanese ET patients. B cell populations, granulocytes/monocytes membrane-bound B cell-activating factor (mBAFF) levels, $B$ cells toll-like receptor 4 (TLR4) expression and intracellular levels of interleukin (IL)-1 $\beta / I L-6$ and the expression of CD69, CD80, and CD86 were quantified by flow cytometry. Serum BAFF concentration was measured by ELISA. 48 healthy adults were used for comparison. $19(35.2 \%)$ of 54 ET patients harbored 8 types of CALR exon 9 mutations including $4(7.4 \%)$ patients with concomitant JAK2V617F mutations. Compared to JAK2V617F mutation, CALR mutations correlated with younger age at diagnosis $(p=0.04)$, higher platelet count $(p=0.004)$, lower hemoglobin level $(p=0.013)$ and lower leukocyte count $(p=0.013)$. Multivariate analysis adjusted for age, sex, follow-up period and hematological parameters confirmed that increased activated B cells were universally present in JAK2-mutated, CALR-mutated and triplenegative ET patients when compared to healthy adults. JAK2- and CALR-mutated ET have significantly higher fraction of B cells with TLR4 expression when compared to triple-negative ET ( $p=0.019$ and 0.02 , respectively). CALR-mutated ET had significantly higher number of CD69-positive activated B cells when compared to triple-negative ET $(p=0.035)$. In conclusion, increased B cell activation is present in ET patients across different mutational subgroups. 


\section{INTRODUCTION}

Essential thrombocythemia (ET) is a $B C L$ $A B L 1$-negative myeloproliferative neoplasm (MPN), and is characterized by increased number of mature megakaryocytes (MKs) in the bone marrow and sustained thrombocytosis in the peripheral blood [1]. ET is associated with an increased risk of hemorrhagic and thrombotic complications and leukemic transformation [1]. Most ET patients can have a normal life expectancy but some may encounter serious events during their disease course. In 2005, the $J A K 2 \mathrm{~V} 617 \mathrm{~F}$ mutation was discovered in MPNs including 50-60\% patients with ET and primary myelofibrosis (PMF) [2-5]. JAK2V617F mutation plays an important role in cytokine-independent hematopoietic stem cells (HSCs) proliferation in MPNs. Also, hypersensitivity of hematopoietic cells to cytokines stimulation is noted in MPNs through the interaction between $J A K 2 \mathrm{~V} 617 \mathrm{~F}$ mutation and various cytokine receptors [6]. Recently, a high frequency of calreticulin (CALR) mutations was discovered in JAK2/ $M P L$-unmutated ET and PMF [7-9]. We and others have reported that $C A L R$ mutations are associated with distinct clinical characteristics including higher platelet counts, lower leukocyte counts and hemoglobin levels, and a lower thrombosis risk when compared to JAK2-mutated ET patients [7-11]. Using in vitro and/or in vivo models, we and others have recently reported that mutant $C A L R$ can activate JAK-STAT signaling pathway through an MPL-dependent mechanism to mediate pathogenic thrombopoiesis [12-18].

CALR is a $46-\mathrm{kDa} \mathrm{Ca} 2+$ binding chaperone protein located in the endoplasmic reticulum, but it can also localize to cell surface and accumulate in extracellular compartments [19]. In addition to ensuring proper protein and glycoprotein folding within the lumen of endoplasmic reticulum, CALR was also found to involve the immune response to pre-apoptotic cancer cells, and early cell surface exposure of CALR was followed by expression and release of heat-shock proteins (e.g. HSP70), and highmobility group I (HMGB1) protein [20]. Recombinant CALR fragment was shown to exhibit potent stimulatory activities against $B$ cells [21, 22]. Recently, we reported that activated B cells are increased in ET patients, and can facilitate platelet production mediated by cytokines, such as interleukin (IL)- $1 \beta$ and IL-6 regardless $J A K 2 \mathrm{~V} 617 \mathrm{~F}$ mutational status [23]. We found that increased production of B cell-activating factor (BAFF) by granulocytes and monocytes up-regulates toll-like receptor 4 (TLR4) expression on B cells and promotes B cell activation in ET patients. Consequently, these activated B cells play a pathogenic role in augmenting thrombocytosis by producing IL-1 $\beta$ and IL-6 in ET patients through cytokine-dependent thrombopoiesis in the bone marrow. However, ET with CALR mutations was not included in our previous study because $C A L R$ mutations have not yet been discovered in MPNs when we conducted our study in 2013. The discovery of CALR mutations in JAK2/MPLunmutated ET patients in December 2013 have prompted us to ask the question that whether increased B cell activation can also be found in ET with CALR mutations similar to that in JAK2V617F-mutated ET [7-9]. Hence, we sought to screen for CALR mutations in a cohort of adult Taiwanese ET patients and to evaluate B cell immune profiles in $J A K 2 \mathrm{~V} 617 \mathrm{~F}$-mutated, CALR-mutated and triple-negative ET in this study.

\section{RESULTS}

\section{Mutational analysis}

Among 54 ET patients (median age at diagnosis 54.5 years; $54 \%$ females; median follow-up 4.4 years), $27(50 \%)$ patients harbored the $J A K 2 \mathrm{~V} 617 \mathrm{~F}$ mutation and one $(1.9 \%)$ patient harbored the $M P L \mathrm{~W} 515 \mathrm{~K}$ mutation. By nucleotide sequencing and HRMA, 19 (35.2\% overall and $68.2 \%$ in $J A K 2 / M P L$-unmutated cases) patients harbored 8 types of CALR exon 9 mutations: 2 type 1 (p.L367fs*46), 10 type 2 (p.K385fs*47), 2 type 3 (p.L367fs*48), 1 type 34 (p.K385fs*47), and 4 other types (one each of p.L367fs*43, p.E370fs*60, p.E371fs*59 and p.E381del). Except p.E381del which is a 3 base-pair inframe deletion, all other CALR exon 9 mutations are indels causing +1 base-pair reading frameshift, with type 2 $(10 / 19,52.6 \%)$ being the most prevalent mutational type. One patient with $J A K 2 \mathrm{~V} 617 \mathrm{~F}$ mutation harbored a single nucleotide polymorphism in CALR exon 9 (c.1142 A > C, rs 143880510). Four (21\%) of the 19 CALR-mutated patients had simultaneous $J A K 2 \mathrm{~V} 617 \mathrm{~F}$ mutation; one each of type 3, p.E370fs*60, p.E371fs*59 and p.E381del, and the latter 3 CALR mutations were only detected by HRMA and required TA-cloning to confirm the presence of mutations indicating that they were low allelic burden mutants. Seven patients (13\%) were triple-negative (TN) for JAK2, CALR and MPL mutations. No DNMT3A exon 23 or $I D H 1 / 2$ exon 4 mutation was detected in this cohort of ET patients. The only one $M P L$-mutated and the 4 CALR/JAK2V617F co-mutated ET patients were excluded from further clinical and molecular correlation analysis to avoid statistical bias.

\section{Clinical and molecular correlates}

In 49 ET patients used for analysis, there was no significant difference in gender among the three major mutational groups. In this cohort, ET patients with CALR mutations had statistically significant longer follow-up (median 6.2 year, $p=0.031$, Table 1), highest platelet count at the time of diagnosis $(p=0.01)$, and lower hemoglobin level at the time of diagnosis $(p=$ 
Table 1: Clinical and laboratory characteristics in healthy adults and patients with essential thrombocythemia.

\begin{tabular}{|c|c|c|c|c|c|c|c|c|c|c|c|}
\hline Variables & HA $(n=48)$ & $\begin{array}{c}J A K 2 \\
\text { mutation } \\
(\mathrm{n}=27)\end{array}$ & $\begin{array}{c}C A L R \\
\text { mutations } \\
(\mathrm{n}=15)\end{array}$ & $\begin{array}{l}\text { Triple- } \\
\text { negative } \\
(n=7)\end{array}$ & $\begin{array}{c}\text { CALR } \\
\text { mutations vs } \\
\text { JAK2 } \\
\text { mutation vs } \\
\text { Triple- } \\
\text { negative } \\
p \text { value }\end{array}$ & $\begin{array}{c}\text { CALR } \\
\text { mutations vs } \\
\text { JAK2 } \\
\text { mutation } \\
p \text { value }\end{array}$ & $\begin{array}{c}\text { CALR } \\
\text { mutations } \\
\text { vs Triple- } \\
\text { negative } \\
p \text { value }\end{array}$ & $\begin{array}{c}J A K 2 \\
\text { mutation } \\
\text { vs Triple- } \\
\text { negative } \\
p \text { value }\end{array}$ & $\begin{array}{c}\text { CALR } \\
\text { mutations } \\
\text { vs HA } \\
\text { p value }\end{array}$ & $\begin{array}{c}\boldsymbol{J} A K 2 \\
\text { mutation } \\
\text { vs HA } \\
p \text { value }\end{array}$ & $\begin{array}{c}\text { Triple- } \\
\text { negative vs } \\
\text { HA } \\
p \text { value }\end{array}$ \\
\hline $\begin{array}{l}\text { Male/Female gender, } \\
\text { n (\%) }\end{array}$ & $\begin{array}{l}15 / 33 \\
(31 / 69)\end{array}$ & $\begin{array}{l}11 / 16 \\
(41 / 59)\end{array}$ & $7 / 8(47 / 53)$ & $3 / 4(43 / 57)$ & NS & NS & NS & NS & - & - & - \\
\hline $\begin{array}{l}\text { Age at diagnosis }(y), \\
\text { median (range) }\end{array}$ & - & $55(25-89)$ & $45(21-76)$ & $52(20-79)$ & NS & 0.04 & NS & NS & - & - & - \\
\hline $\begin{array}{l}\text { Follow-up (y), } \\
\text { median (range) }\end{array}$ & - & $\begin{array}{c}3.6 \\
(0.1-20.8)\end{array}$ & $\begin{array}{c}6.2 \\
(0.8-13.4)\end{array}$ & $\begin{array}{c}3.3(0.1- \\
10.3)\end{array}$ & 0.031 & 0.019 & 0.039 & NS & - & - & - \\
\hline $\begin{array}{l}\text { Hemoglobin at } \\
\text { diagnosis ( } g / d L), \\
\text { median (range) }\end{array}$ & - & $\begin{array}{c}13.5 \\
(8.6-17.1)\end{array}$ & $\begin{array}{c}11.9 \\
(8.5-15.2)\end{array}$ & $\begin{array}{c}12.9 \\
(10.1-15.2)\end{array}$ & 0.037 & 0.013 & NS & NS & - & - & - \\
\hline $\begin{array}{l}\text { WBC at diagnosis } \\
\left(\times 10^{9} / \mathrm{L}\right) \text {, median } \\
\text { (range) }\end{array}$ & - & $\begin{array}{c}12.3 \\
(5.7-27.7)\end{array}$ & $\begin{array}{c}8.7 \\
(4.3-17.5)\end{array}$ & $\begin{array}{c}7.8 \\
(5.3-10.2)\end{array}$ & 0.002 & 0.013 & NS & 0.002 & - & - & - \\
\hline $\begin{array}{l}\text { Platelet at diagnosis } \\
\left(\mathrm{x} 10^{9} / \mathrm{L}\right) \text {, median } \\
\text { (range) }\end{array}$ & - & $\begin{array}{c}948 \\
(335-1437)\end{array}$ & $\begin{array}{c}1275 \\
(759-2606)\end{array}$ & $\begin{array}{c}900 \\
(608-1374)\end{array}$ & 0.01 & 0.004 & 0.039 & NS & - & - & - \\
\hline $\begin{array}{l}\text { Hemoglobin at } \\
\text { testing ( } \mathrm{g} / \mathrm{dL} \text { ), } \\
\text { median (range) }\end{array}$ & $\begin{array}{c}12.9 \\
(10.3-16.7)\end{array}$ & $\begin{array}{c}13.4 \\
(7.2-15.9)\end{array}$ & $\begin{array}{c}12.5 \\
(9.1-15)\end{array}$ & $\begin{array}{c}13.3 \\
(10.1-15.6)\end{array}$ & NS & NS & NS & NS & NS & 0.039 & NS \\
\hline $\begin{array}{l}\text { WBC at testing } \\
\left(x 10^{9} / \mathrm{L}\right), \text { median } \\
\text { (range), } \mathrm{n}=56\end{array}$ & $5.5(3.9-7)$ & $\begin{array}{c}12.0 \\
(6.8-21.8)\end{array}$ & $8.3(4-13.8)$ & $\begin{array}{c}7.8 \\
(4.6-8.6)\end{array}$ & $<0.001$ & 0.001 & NS & 0.001 & 0.005 & $<0.001$ & 0.034 \\
\hline $\begin{array}{l}\text { Platelet at testing } \\
\left(\times 10^{9} / \mathrm{L}\right), \text { median } \\
\text { (range) }\end{array}$ & $\begin{array}{c}241.5 \\
(118-366)\end{array}$ & $\begin{array}{c}842 \\
(449-1227)\end{array}$ & $\begin{array}{c}734(247-22 \\
15)\end{array}$ & $\begin{array}{c}824 \\
(551-1127)\end{array}$ & NS & NS & NS & NS & $<0.001$ & $<0.001$ & $<0.001$ \\
\hline $\begin{array}{l}\text { Cytoreductive } \\
\text { therapy with } \\
\text { hydroxyurea, n (\%) }\end{array}$ & - & $20(74.1)$ & $11(73.3)$ & $3(42.9)$ & NS & NS & NS & NS & - & - & - \\
\hline
\end{tabular}

Abbreviations: HA, healthy adults; No. and n, number; NS, not significant; WBC, white blood cell; y, year.

0.037). When compared with JAK2V617F-mutated ET patients, CALR mutations also correlated with younger age at diagnosis $(p=0.04)$ and lower leukocyte count $(p=0.013) . J A K 2 \mathrm{~V} 617 \mathrm{~F}$ mutation was associated with leukocytosis $(p=0.002)$ and white blood cell count was lowest in TN ET patients. 
Table 2: Univariate analysis of B cell immune profiles in healthy adults and patients with essential thrombocythemia.

\begin{tabular}{|c|c|c|c|c|c|c|c|c|c|c|c|}
\hline Variables & HA $(n=48)$ & $\begin{array}{c}J A K 2 \\
\text { mutation } \\
(n=27)\end{array}$ & $\begin{array}{c}C A L R \\
\text { mutations } \\
(n=15)\end{array}$ & $\begin{array}{c}\text { Triple- } \\
\text { negative } \\
(n=7)\end{array}$ & \begin{tabular}{|c}
$C A L R$ \\
mutations \\
vs $J A K 2$ \\
mutation \\
vs Triple- \\
negative \\
$p$ value
\end{tabular} & $\begin{array}{c}C A L R \\
\text { mutations } \\
\text { vs } J A K 2 \\
\text { mutation } \\
p \text { value }\end{array}$ & $\begin{array}{c}\text { CALR } \\
\text { mutations } \\
\text { vs Triple- } \\
\text { negative } \\
p \text { value }\end{array}$ & $\begin{array}{c}J A K 2 \\
\text { mutation } \\
\text { vs Triple- } \\
\text { negative } \\
p \text { value }\end{array}$ & $\begin{array}{c}C A L R \\
\text { mutations } \\
\text { vs HA } \\
p \text { value }\end{array}$ & $\begin{array}{c}J A K 2 \\
\text { mutation } \\
\text { vs HA } \\
p \text { value }\end{array}$ & $\begin{array}{c}\text { Triple- } \\
\text { negative vs } \\
\text { HA } \\
p \text { value }\end{array}$ \\
\hline $\begin{array}{l}\text { CD19+ B cells } \\
(/ \mu \mathrm{L}), \text { median } \\
\text { (range), } n=71\end{array}$ & $\begin{array}{c}230.5(143- \\
455)\end{array}$ & $\begin{array}{c}129.0 \\
(25.8-358)\end{array}$ & $\begin{array}{c}121.8 \\
(17.8-318)\end{array}$ & $\begin{array}{c}97.2(38.1- \\
219.5)\end{array}$ & NS & NS & NS & NS & 0.001 & $<0.001$ & 0.001 \\
\hline \begin{tabular}{|l|} 
Early \\
transitional B \\
cells $(\mathrm{T} 1)(/ \mu \mathrm{L})$, \\
median (range), \\
$\mathrm{n}=61$
\end{tabular} & $3(1-11)$ & $\begin{array}{l}1.1(0.0- \\
15.5)\end{array}$ & $2(0.0-19.4)$ & $2.5(1-10)$ & NS & NS & NS & NS & NS & NS & NS \\
\hline $\begin{array}{l}\text { Late transitional } \\
\mathrm{B} \text { cells }(\mathrm{T} 2) \\
(/ \mu \mathrm{L}), \text { median } \\
(\text { range }), \mathrm{n}=61\end{array}$ & $7(3-15)$ & $15(1-46)$ & $\begin{array}{c}14(0.4- \\
29.5)\end{array}$ & $9.2(2-46)$ & NS & NS & NS & NS & NS & NS & NS \\
\hline $\begin{array}{l}\text { Pre-germinal } \\
\text { center B cells } \\
(/ \mu \mathrm{L}), \text { median } \\
\text { (range), } n=61\end{array}$ & $4(1-24)$ & $7(2-17.6)$ & $6.6(2-19)$ & $4.0(3-25)$ & NS & NS & NS & NS & NS & NS & NS \\
\hline $\begin{array}{l}\text { Memory B cells } \\
(/ \mu \mathrm{L}), \text { median } \\
\text { (range), } \mathrm{n}=61 \\
\end{array}$ & $\begin{array}{c}75.5(32- \\
181)\end{array}$ & $\begin{array}{l}34(6.8- \\
108)\end{array}$ & $\begin{array}{l}34(3.4- \\
145)\end{array}$ & $\begin{array}{c}28.5(20- \\
165)\end{array}$ & NS & NS & NS & NS & $<0.001$ & $<0.001$ & NS \\
\hline $\begin{array}{l}\text { Plasmablast } \\
(/ \mu \mathrm{L}), \text { median } \\
\text { (range), } \mathrm{n}=61\end{array}$ & $0.0(0.0-1)$ & $0.4(0.0-4)$ & $0.3(0.0-3)$ & $0.5(0.0-2)$ & NS & NS & NS & NS & $<0.001$ & $<0.001$ & 0.025 \\
\hline $\begin{array}{l}\text { Naive B cells } \\
(/ \mu \mathrm{L}), \text { median } \\
\text { (range), } \mathrm{n}=61\end{array}$ & $\begin{array}{c}134.5(75- \\
238)\end{array}$ & $\begin{array}{l}65.6(5.8- \\
293)\end{array}$ & $\begin{array}{l}45.8(5.8- \\
223)\end{array}$ & $\begin{array}{c}57.5(16- \\
591)\end{array}$ & NS & NS & NS & NS & 0.003 & 0.01 & 0.014 \\
\hline $\begin{array}{l}\text { MFI of mBAFF } \\
\text { on granulocytes, } \\
n=63\end{array}$ & $\begin{array}{c}6.7(4.6- \\
8.3)\end{array}$ & $\begin{array}{c}25.4(7.8- \\
75.2)\end{array}$ & $\begin{array}{c}34.2(10.2- \\
67.7)\end{array}$ & $\begin{array}{c}33.7(4.5- \\
65.4)\end{array}$ & NS & NS & NS & NS & $<0.001$ & $<0.001$ & 0.007 \\
\hline $\begin{array}{l}\text { MFI of mBAFF } \\
\text { on monocytes, } \\
n=62\end{array}$ & $\begin{array}{c}7.6(2.8- \\
8.0)\end{array}$ & $\begin{array}{c}14.2(3.5- \\
54.6)\end{array}$ & \begin{tabular}{|c|}
$28.9(4.4-$ \\
$49.4)$
\end{tabular} & $\begin{array}{c}14.3(3.2- \\
40.7)\end{array}$ & NS & NS & NS & NS & $<0.001$ & $<0.001$ & 0.005 \\
\hline \begin{tabular}{|l|} 
Serum BAFF \\
level $(\mathrm{ng} / \mathrm{mL})$, \\
$\mathrm{n}=66$
\end{tabular} & $\begin{array}{l}1.1(0.6- \\
2.4)\end{array}$ & $\begin{array}{c}2.3(0.8- \\
4.9)\end{array}$ & $\begin{array}{l}1.6(0.9- \\
3.9)\end{array}$ & $\begin{array}{c}1.8(1.4- \\
3.8)\end{array}$ & 0.049 & 0.02 & NS & NS & 0.015 & $<0.001$ & 0.001 \\
\hline $\begin{array}{l}\text { IL-6 in B cells } \\
(\%), n=39\end{array}$ & $\begin{array}{l}1.0(0.2- \\
1.9)\end{array}$ & $\begin{array}{l}6.7(2.6- \\
9.6)\end{array}$ & $\begin{array}{l}6.8(4.0- \\
13.7)\end{array}$ & $\begin{array}{l}8.2(4.5- \\
10.3)\end{array}$ & NS & NS & NS & NS & $<0.001$ & $<0.001$ & $<0.001$ \\
\hline $\begin{array}{l}\text { IL- } 1 \beta \text { in } B \text { cells } \\
(\%), n=39\end{array}$ & $\begin{array}{c}4.8(0.9- \\
13.4)\end{array}$ & $\begin{array}{c}11.5(1.4- \\
32.5)\end{array}$ & $\begin{array}{c}15.4(4.6- \\
32.6)\end{array}$ & $\begin{array}{c}12.9(3.6- \\
41.7)\end{array}$ & NS & NS & NS & NS & 0.002 & 0.002 & 0.012 \\
\hline $\begin{array}{l}\text { TLR4 in B cells } \\
(\%), n=54\end{array}$ & $\begin{array}{l}2.3(0.3- \\
3.0)\end{array}$ & $\begin{array}{c}4.5(0.4- \\
24.2)\end{array}$ & $\begin{array}{c}11.3(2.3- \\
22.8)\end{array}$ & $\begin{array}{l}3.4(1.0- \\
5.4)\end{array}$ & 0.021 & NS & 0.001 & NS & $<0.001$ & 0.001 & 0.02 \\
\hline $\begin{array}{l}\text { CD69+ B cells } \\
(/ \mu \mathrm{L}), \text { median } \\
\text { (range), } \mathrm{n}=48\end{array}$ & $\begin{array}{c}2.2(1.0- \\
4.6)\end{array}$ & $\begin{array}{c}12.5(0.6- \\
39.1)\end{array}$ & \begin{tabular}{|}
$20.8(2.5-$ \\
$51.4)$
\end{tabular} & $\begin{array}{c}7.6(1.8- \\
18.6)\end{array}$ & NS & NS & 0.048 & NS & $<0.001$ & 0.002 & NS \\
\hline $\begin{array}{l}\text { CD80+ B cells } \\
(/ \mu \mathrm{L}), \text { median } \\
\text { (range), } n=46\end{array}$ & $\begin{array}{c}9.2(0.8- \\
12.5)\end{array}$ & $\begin{array}{c}9.0(1.9- \\
79.1)\end{array}$ & \begin{tabular}{|c|}
$13.8(1.0-$ \\
$72.6)$
\end{tabular} & $\begin{array}{c}10.0(1.6- \\
44.7)\end{array}$ & NS & NS & NS & NS & 0.036 & NS & NS \\
\hline $\begin{array}{l}\text { CD86+ B cells } \\
(/ \mu \mathrm{L}), \text { median } \\
\text { (range), } \mathrm{n}=46\end{array}$ & $\begin{array}{c}10.9(3.0- \\
41.9)\end{array}$ & $\begin{array}{c}26.3(4.3- \\
101.6)\end{array}$ & $\begin{array}{c}18.3(5.9- \\
63.4)\end{array}$ & $\begin{array}{c}24.2(8.0- \\
82.3)\end{array}$ & NS & NS & NS & NS & 0.041 & 0.012 & NS \\
\hline
\end{tabular}

Abbreviations: BAFF, B cell-activating factor; HA, healthy adults; IL, interleukin; mBAFF, membrane-bound B cell-activating factor; MFI, mean fluorescence intensity; No. and n, number; NS, not significant; TLR4, toll-like receptor 4; WBC, white blood cell; y, year.

\section{Distribution of B cells and B cell subsets}

Among 49 ET patients in the three major mutational groups, there were no significant differences in the number of total B cells and all the B cell subset populations (Table 2). When compared to healthy adults, ET patients had significantly lower numbers of total B cells and naïve B cells, but had significantly higher number of plasmablast in all three mutational groups. The number of memory B cells was statistically lower in CALR- and JAK2 mutatedET patients when compared with healthy adults. There were no statistically significant differences in the numbers of early and late transitional B cells and pre-germinal 
Table 3: Correlation of platelet count at testing, serum BAFF levels, and B cell immune profiles in this study.

\begin{tabular}{|l|c|c|c|c|c|c|c|c|}
\hline \multirow{2}{*}{ Variables } & \multicolumn{2}{|c|}{ Platelet at testing } & \multicolumn{2}{c|}{$\begin{array}{c}\text { MFI of mBAFF on } \\
\text { granulocytes }\end{array}$} & \multicolumn{2}{c|}{$\begin{array}{c}\text { MFI of mBAFF on } \\
\text { monocytes }\end{array}$} & \multicolumn{2}{c|}{ Serum BAFF levels } \\
\cline { 2 - 9 } & $\begin{array}{c}\text { Spearman's } \\
\text { rho }\end{array}$ & $\boldsymbol{p}$ value & $\begin{array}{c}\text { Spearman's } \\
\text { rho }\end{array}$ & $\boldsymbol{p}$ value & $\begin{array}{c}\text { Spearman's } \\
\text { rho }\end{array}$ & $\boldsymbol{p}$ value & $\begin{array}{c}\text { Spearman's } \\
\text { rho }\end{array}$ & $\boldsymbol{p}$ value \\
\hline $\begin{array}{l}\text { MFI of mBAFF } \\
\text { on granulocytes }\end{array}$ & 0.377 & 0.002 & - & - & 0.786 & $<0.001$ & 0.29 & 0.021 \\
\hline $\begin{array}{l}\text { MFI of mBAFF } \\
\text { on monocytes }\end{array}$ & 0.312 & 0.011 & 0.786 & $<0.001$ & - & - & 0.304 & 0.016 \\
\hline $\begin{array}{l}\text { Serum BAFF } \\
\text { levels }\end{array}$ & 0.486 & $<0.001$ & 0.29 & 0.021 & 0.304 & 0.016 & - & - \\
\hline IL-6 in B cells & 0.61 & $<0.001$ & 0.545 & $<0.001$ & 0.398 & 0.009 & 0.572 & $<0.001$ \\
\hline IL-1 $\beta$ in B cells & 0.543 & $<0.001$ & 0.55 & $<0.001$ & 0.472 & 0.002 & 0.293 & NS \\
\hline CD69+ B cells & 0.325 & 0.021 & 0.388 & 0.005 & 0.161 & NS & 0.225 & NS \\
\hline CD86+ B cells & 0.26 & NS & 0.42 & 0.003 & 0.252 & NS & 0.141 & NS \\
\hline
\end{tabular}

Abbreviations: BAFF, B cell-activating factor; IL, interleukin; mBAFF, membrane-bound B cell-activating factor; MFI, mean fluorescence intensity; NS, not significant.

center B cells between ET patients and healthy adults.

\section{B cell immune profiles}

Among 49 ET patients in the three major mutational groups, the B cell immune profiles in $34(69.4 \% ; 19$ JAK2V617F-mutated, 9 CALR-mutated and $6 \mathrm{TN}$ ) patients had been previously described [23]. When compared with $J A K 2$ V617F-mutated and TN ET patients, CALR mutations correlated with significantly lower serum BAFF level (median $1.6 \mathrm{ng} / \mathrm{mL}, p=0.049$ ) (Figure 1A) and higher fraction of $\mathrm{B}$ cells with TLR4 expression (median $11.3 \%, p=0.021$ ) (Figure 2A). Besides, ET patients with CALR mutations had statistically higher number of CD69positive activated B cells when compared to TN group (median: $20.8 / \mu \mathrm{L} v s 7.6 / \mu \mathrm{L}, p=0.048$ ) (Figure $3 \mathrm{~A}$ ). There were no significant differences in mean fluorescence intensity (MFI) of mBAFF on both granulocytes and monocytes (Figure $1 \mathrm{~B}$ and $1 \mathrm{C}$, respectively), in the fraction of B cells with intracellular IL-1 $\beta$ or IL-6 expression (Figure 2B and 2C, respectively), and the numbers of CD80-positive and CD86-positive activated $\mathrm{B}$ cells among the three mutational groups of ET patients (Figure 3B and 3C, respectively).

When compared to healthy adults, patients with ET had statistically significant higher serum BAFF level and higher MFI of mBAFF on both granulocytes and monocytes (Figure 1), and higher fraction of $B$ cells with TLR4 expression and higher fractions of $B$ cells with intracellular IL-1 $\beta$ and IL-6 expression irrespective of their genotypes (Figure 2) (Table 2). Although ET patients had significantly lower numbers of CD19-positive B cells and naïve B cells when compared to healthy adults, ET patients with CALR and JAK2 mutations had statistically higher numbers of CD69-positive and CD86-positive activated B cells (Figure 3A and 3C, respectively). 38 $(70.4 \%)$ of 54 ET patients were treated with hydroxyurea to lower their blood counts in this cohort. There were no significant differences in all the B cells immune profiles in ET patients with or without hydroxyurea treatment, except lower IL-1 $\beta$ expression level in B cells (median $6.9 \% v s$ $16.4 \%, p=0.014$ ) was found in ET patients being treated with hydroxyurea (Table 1 and Supplementary Table S1).

In this study, platelet count at testing had moderately positive correlation with the fractions of B cells with intracellular IL-1 $\beta$ and IL-6 expression (Table 3). MFI of mBAFF on granulocytes had strong positive correlation with MFI of mBAFF on monocytes, and had moderately positive correlation with the fractions of $\mathrm{B}$ cells with intracellular IL-1 $\beta$ and IL-6 expression. In addition, serum BAFF levels had moderately positive correlation with the fraction of B cells with intracellular IL-6 expression. Interestingly, only MFI of mBAFF on granulocytes, but not MFI of mBAFF on monocytes or the serum BAFF levels, had weak positive correlation with the numbers of CD69-positive and CD86-positive activated B cells in our cohort. We also analyzed the correlation between platelet count, serum BAFF levels, and B cell immune profiles in the group of healthy controls. Platelet count of healthy controls only had moderately negative correlation with the MFI of mBAFF on monocytes (Spearman's rho $=-0.625$, 


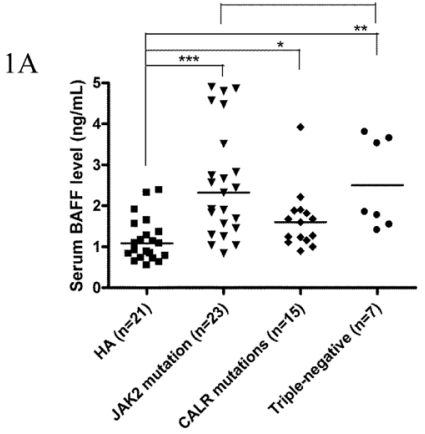

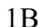

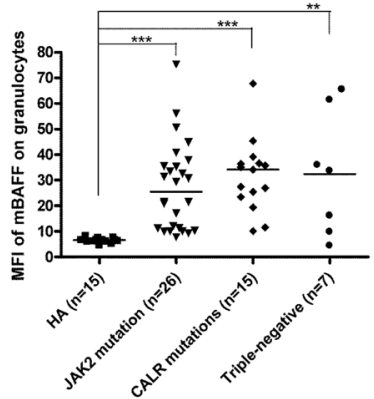

1C

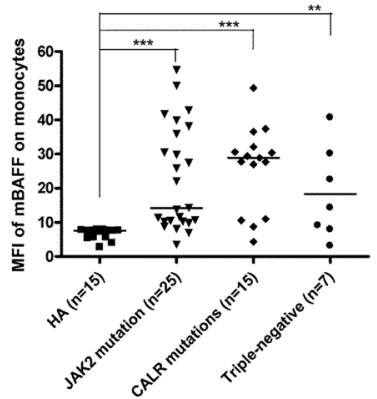

Figure 1: Elevated serum BAFF levels and higher membrane-bound BAFF expression in peripheral granulocytes and monocytes of ET patients. 1A, Elevated serum BAFF levels were found in ET patients, regardless of genotypes compared to healthy adults. CALR-mutated ET patients had lowest serum BAFF levels compared to JAK2-mutated and triple-negative ET patients in univariate analysis. 1B and 1C, Membrane-bound BAFF expression in peripheral granulocytes and monocytes was higher in ET patients, regardless of genotypes compared to healthy adults, respectively. Median values are indicated by the short horizontal bars. Asterisks represent significant differences between groups. ${ }^{*} p<0.05,{ }^{* *} p<0.01,{ }^{* * *} p<0.001$.

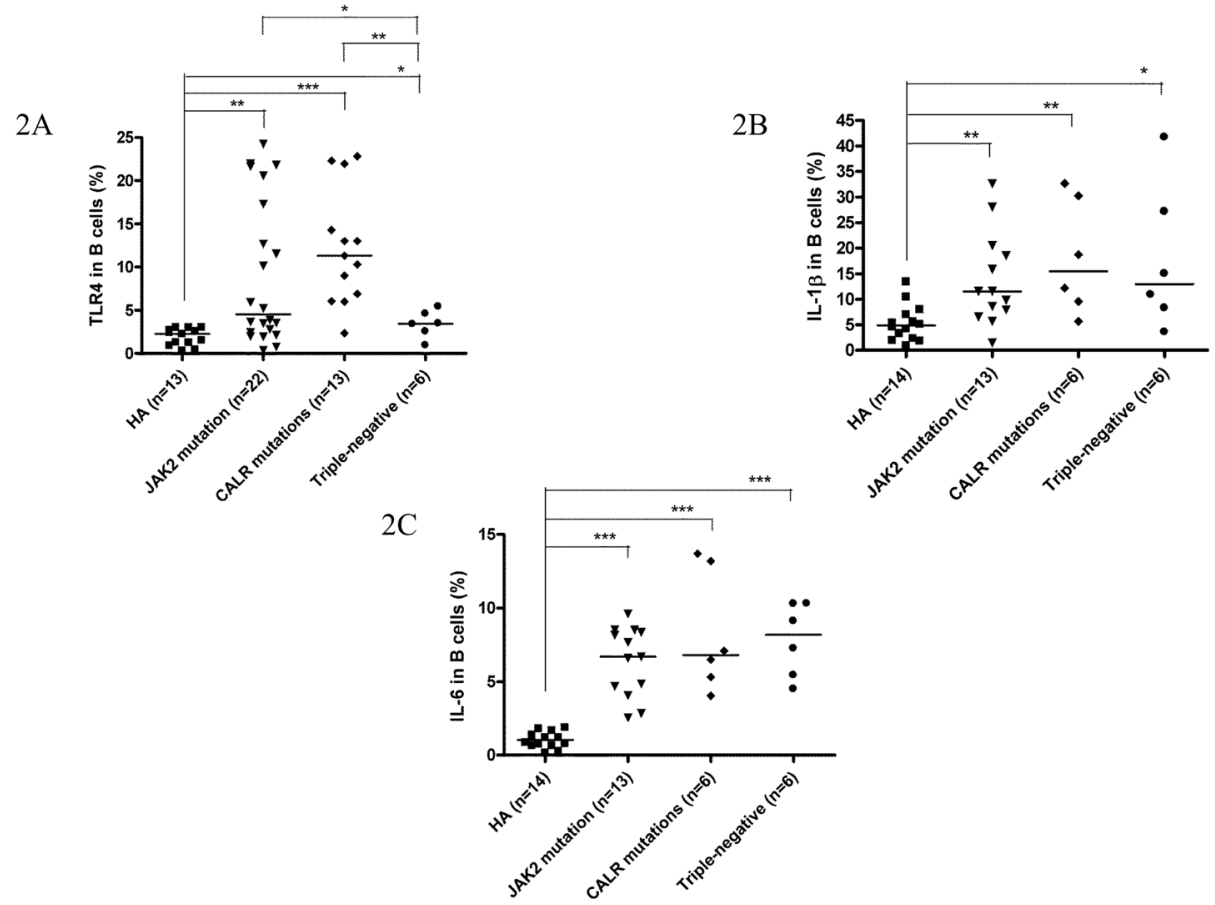

Figure 2: Fractions of activated B cells with TLR4 expression, and IL-1 $\beta$ and IL-6 production were higher in ET patients. 2A, B cells from patients with ET, regardless of genotypes expressed significantly higher levels of TLR4 compared to healthy adults. CALR-mutated ET patients had highest TLR4 expression compared to JAK2-mutated and triple-negative ET patients. 2B and 2C, B cells from patients with ET, regardless of genotypes expressed significantly higher levels of IL-1 $\beta$ and IL- 6 compared to healthy adults, respectively. Median values are indicated by the short horizontal bars. Asterisks represent significant differences between groups. ${ }^{*} p<0.05$, $* * p<0.01, * * * p<0.001$ 
Table 4: Comparison of $B$ cell immune profiles between healthy adults and patients with essential thrombocythemia using linear regression model adjusted for hematological parameters.

\begin{tabular}{|c|c|c|c|c|c|c|}
\hline \multirow{2}{*}{ Variables } & \multirow{2}{*}{ ET subgroups } & \multicolumn{2}{|c|}{$\begin{array}{l}\text { Unstandardized } \\
\text { Coefficients }\end{array}$} & \multirow[t]{2}{*}{$p$ value } & \multicolumn{2}{|c|}{ 95\% Confidence Interval for B } \\
\hline & & B & Std. Error & & Lower Bound & Upper Bound \\
\hline \multirow{3}{*}{ CD19+ B cells $(/ \mu \mathrm{L})$} & $J A K 2$-mutated & -109.918 & 42.713 & 0.013 & -195.846 & -23.990 \\
\hline & CALR-mutated & -102.613 & 40.102 & 0.014 & -183.289 & -21.938 \\
\hline & $\mathrm{TN}$ & -148.166 & 46.096 & 0.002 & -240.899 & -55.433 \\
\hline \multirow{3}{*}{$\begin{array}{c}\text { Neutrophil mBAFF } \\
\text { MFI }\end{array}$} & $J A K 2$-mutated & 25.969 & 9.115 & 0.006 & 7.642 & 44.297 \\
\hline & $C A L R$-mutated & 33.242 & 8.565 & $<0.001$ & 16.020 & 50.463 \\
\hline & $\mathrm{TN}$ & 34.018 & 9.410 & 0.001 & 15.099 & 52.938 \\
\hline \multirow{3}{*}{ Monocyte mBAFF MFI } & $J A K 2$-mutated & 14.897 & 7.287 & 0.047 & 0.237 & 29.556 \\
\hline & CALR-mutated & 23.159 & 6.779 & 0.001 & 9.522 & 36.796 \\
\hline & $\mathrm{TN}$ & 16.591 & 7.446 & 0.031 & 1.612 & 31.571 \\
\hline \multirow{3}{*}{$\begin{array}{l}\text { Serum BAFF levels } \\
(\mathrm{ng} / \mathrm{ml})\end{array}$} & $J A K 2$-mutated & 0.915 & 0.625 & NS & -0.343 & 2.173 \\
\hline & $C A L R$-mutated & 0.194 & 0.586 & NS & -0.986 & 1.373 \\
\hline & $\mathrm{TN}$ & 1.102 & 0.643 & NS & -0.194 & 2.397 \\
\hline \multirow{3}{*}{ Total B IL-6 \% } & $J A K 2$-mutated & 4.488 & 1.912 & 0.027 & 0.551 & 8.425 \\
\hline & CALR-mutated & 4.906 & 2.337 & 0.046 & 0.093 & 9.719 \\
\hline & $\mathrm{TN}$ & 5.463 & 1.724 & 0.004 & 1.913 & 9.014 \\
\hline \multirow{3}{*}{ Total B IL-1 $\beta \%$} & $J A K 2$-mutated & 11.566 & 7.807 & NS & -4.513 & 27.644 \\
\hline & $C A L R$-mutated & 16.529 & 9.544 & NS & -3.128 & 36.186 \\
\hline & $\mathrm{TN}$ & 14.697 & 7.040 & 0.047 & 0.199 & 29.196 \\
\hline \multirow{3}{*}{ Total B TLR4 \% } & $J A K 2$-mutated & 14.090 & 4.281 & 0.002 & 5.439 & 22.742 \\
\hline & $C A L R$-mutated & 14.262 & 3.746 & $<0.001$ & 6.692 & 21.832 \\
\hline & $\mathrm{TN}$ & 5.888 & 4.378 & NS & -2.961 & 14.737 \\
\hline \multirow{3}{*}{ CD69+ B cells $(/ \mu \mathrm{L})$} & $J A K 2$-mutated & 35.629 & 9.431 & 0.001 & 16.440 & 54.817 \\
\hline & $C A L R$-mutated & 34.581 & 7.583 & $<0.001$ & 19.153 & 50.008 \\
\hline & $\mathrm{TN}$ & 19.206 & 9.302 & 0.047 & 0.282 & 38.130 \\
\hline \multirow{3}{*}{ CD80+ B cells $(/ \mu \mathrm{L})$} & $J A K 2$-mutated & 18.875 & 15.117 & $\mathrm{NS}$ & -11.956 & 49.705 \\
\hline & CALR-mutated & 15.519 & 12.409 & $\mathrm{NS}$ & -9.790 & 40.828 \\
\hline & $\mathrm{TN}$ & 16.876 & 14.963 & NS & -13.640 & 47.393 \\
\hline \multirow{3}{*}{ CD86 $+\mathrm{B}$ cells $(/ \mu \mathrm{L})$} & $J A K 2$-mutated & 38.875 & 17.586 & 0.035 & 3.007 & 74.742 \\
\hline & CALR-mutated & 27.556 & 14.437 & NS & -1.888 & 57.000 \\
\hline & $\mathrm{TN}$ & 33.042 & 17.407 & NS & -2.460 & 68.545 \\
\hline
\end{tabular}

Abbreviations: mBAFF, membrane-bound B cell-activating factor; IL: interleukin; MFI, mean fluorescence intensity; NS, not significant; Std., standard; TLR4: toll-like receptor 4; TN, triple-negative.

$p=0.013$ ) suggesting that the platelet count of healthy controls did not have obvious correlation with their B cell immune profiles.

\section{Multivariate analysis of $B$ cell immune profiles in ET}

The results of multivariate analysis using linear regression model adjusted for multiple parameters 
Table 5: Comparison of B cell immune profiles among patients with essential thrombocythemia using linear regression model adjusted for age, sex, follow-up period and hematological parameters.

\begin{tabular}{|c|c|c|c|c|c|c|c|c|c|c|c|}
\hline \multirow[t]{3}{*}{ Variables } & \multirow{3}{*}{$\begin{array}{c}\text { ET } \\
\text { subgroups }\end{array}$} & \multicolumn{5}{|c|}{$C A L R$-mutated group as control } & \multicolumn{5}{|c|}{$J A K 2$-mutated group as control } \\
\hline & & \multicolumn{2}{|c|}{$\begin{array}{l}\text { Unstandardized } \\
\text { Coefficients }\end{array}$} & \multirow[t]{2}{*}{$\begin{array}{c}p \\
\text { value }\end{array}$} & \multicolumn{2}{|c|}{$\begin{array}{l}\text { 95\% Confidence } \\
\text { Interval for B }\end{array}$} & \multicolumn{2}{|c|}{$\begin{array}{l}\text { Unstandardized } \\
\text { Coefficients }\end{array}$} & \multirow[t]{2}{*}{$\begin{array}{c}p \\
\text { value }\end{array}$} & \multicolumn{2}{|c|}{$\begin{array}{l}\text { 95\% Confidence } \\
\text { Interval for B }\end{array}$} \\
\hline & & B & $\begin{array}{l}\text { Std. } \\
\text { Error }\end{array}$ & & $\begin{array}{l}\text { Lower } \\
\text { Bound }\end{array}$ & $\begin{array}{l}\text { Upper } \\
\text { Bound }\end{array}$ & $\mathbf{B}$ & $\begin{array}{l}\text { Std. } \\
\text { Error }\end{array}$ & & $\begin{array}{l}\text { Lower } \\
\text { Bound }\end{array}$ & $\begin{array}{l}\text { Upper } \\
\text { Bound }\end{array}$ \\
\hline \multirow{3}{*}{$\begin{array}{c}\text { Serum } \\
\text { BAFF } \\
\text { levels } \\
(\mathrm{ng} / \mathrm{ml})\end{array}$} & $\begin{array}{l}J A K 2- \\
\text { mutated }\end{array}$ & 0.436 & 0.479 & NS & -0.536 & 1.408 & - & - & - & - & - \\
\hline & $\begin{array}{l}\text { CALR- } \\
\text { mutated }\end{array}$ & - & - & - & - & - & -0.436 & 0.479 & NS & -1.408 & 0.536 \\
\hline & $\mathrm{TN}$ & 0.571 & 0.578 & NS & -0.601 & 1.743 & 0.135 & 0.577 & NS & -1.035 & 1.304 \\
\hline \multirow[t]{3}{*}{$\begin{array}{c}\text { Total B } \\
\text { TLR4 \% }\end{array}$} & $\begin{array}{l}J A K 2- \\
\text { mutated }\end{array}$ & 0.437 & 2.759 & NS & -5.183 & 6.057 & - & - & - & - & - \\
\hline & $\begin{array}{l}\text { CALR- } \\
\text { mutated }\end{array}$ & - & - & - & - & - & -0.437 & 2.759 & NS & -6.057 & 5.183 \\
\hline & TN & -8.169 & 3.329 & 0.02 & -14.951 & -1.388 & -8.606 & 3.467 & 0.019 & -15.669 & -1.543 \\
\hline \multirow{3}{*}{$\begin{array}{c}\text { CD69+ B } \\
\text { cells } \\
(/ \mu \mathrm{L})\end{array}$} & $\begin{array}{l}J A K 2- \\
\text { mutated }\end{array}$ & -1.303 & 7.025 & NS & -15.801 & 13.196 & - & - & - & - & - \\
\hline & $\begin{array}{l}\text { CALR- } \\
\text { mutated }\end{array}$ & - & - & - & - & - & 1.303 & 7.025 & NS & -13.196 & 15.801 \\
\hline & $\mathrm{TN}$ & -18.480 & 8.265 & 0.035 & -35.539 & -1.421 & -17.177 & 8.605 & NS & -34.936 & 0.582 \\
\hline \multirow{3}{*}{$\begin{array}{c}\text { CD80+ B } \\
\text { cells } \\
(/ \mu \mathrm{L})\end{array}$} & $\begin{array}{l}J A K 2- \\
\text { mutated }\end{array}$ & 6.135 & $\begin{array}{c}11.38 \\
2 \\
\end{array}$ & NS & -17.470 & 29.740 & - & - & - & - & - \\
\hline & $\begin{array}{l}\text { CALR- } \\
\text { mutated }\end{array}$ & - & - & - & - & - & -6.135 & $\begin{array}{c}11.38 \\
2 \\
\end{array}$ & NS & -29.740 & 17.470 \\
\hline & TN & 3.273 & $\begin{array}{c}13.17 \\
5 \\
\end{array}$ & NS & -24.051 & 30.597 & -2.862 & $\begin{array}{c}13.17 \\
5 \\
\end{array}$ & NS & -30.185 & 24.462 \\
\hline \multirow{3}{*}{$\begin{array}{c}\mathrm{CD} 86+\mathrm{B} \\
\text { cells } \\
(/ \mu \mathrm{L})\end{array}$} & $\begin{array}{l}J A K 2- \\
\text { mutated }\end{array}$ & 16.243 & $\begin{array}{c}13.69 \\
6\end{array}$ & NS & -12.161 & 44.647 & - & - & - & - & - \\
\hline & $\begin{array}{c}\text { CALR- } \\
\text { mutated }\end{array}$ & - & - & - & - & - & -16.243 & $\begin{array}{c}13.69 \\
6 \\
\end{array}$ & NS & -44.647 & 12.161 \\
\hline & $\mathrm{TN}$ & 11.584 & $\begin{array}{c}15.85 \\
4\end{array}$ & NS & -21.294 & 44.463 & -4.658 & $\begin{array}{c}15.85 \\
4\end{array}$ & NS & -37.537 & 28.221 \\
\hline
\end{tabular}

Abbreviations: BAFF, B cell-activating factor; NS, not significant; Std., standard; TLR4: toll-like receptor 4; TN, triplenegative.

confirmed that increased activated CD69+ B cells were universally present in JAK2-mutated, CALR-mutated and triple-negative ET patients when compared to healthy adults, although the number of total B- cells was significantly lower in ET patients (Table 4). Activated $\mathrm{B}$ cells were characterized by the expression of CD69 and CD86, increased intracellular IL-6 and IL-1 $\beta$ levels, and higher expression of TLR4. Interestingly, peripheral granulocytes and monocytes mBAFF expression was significantly higher in ET patients compared to healthy controls. JAK2-mutated and CALR-mutated ET patients had significantly higher number of B-cells expressing TLR4 and IL-6, and TN ET patients had significantly higher number of B-cells expressing IL-6 and IL-1 $\beta$ (Table 4). TN ET patients had significantly lower number of B-cells expressing TLR4 when compared to CALR- mutated and $J A K 2$-mutated ET patients (Table 5). TN ET patients also had significantly lower number of CD69+ B-cells when compared to $C A L R$-mutated ET patients.

\section{DISCUSSION}

CALR mutations have been found to have phenotypic and prognostic significances in patients with ET from both Caucasian and Chinese populations [7, 8, 11, 24-27]. In this cohort of adult Taiwanese ET patients, CALR mutations were found to have a similar phenotypic correlation with higher platelet count, lower hemoglobin level and younger age at diagnosis. However, we detected a higher frequency of type 2 CALR mutation (10 of 19 patients) in this study while there was only 2 type 1 CALR mutation detected. These results are contradictory to the 
Table 6: Characteristics and the frequency of CALR and JAK2V617F co-mutations in patients with essential thrombocythemia.

\begin{tabular}{|c|c|c|c|c|c|c|}
\hline \multirow[t]{2}{*}{ Author } & \multirow[t]{2}{*}{$\begin{array}{c}\text { Populatio } \\
\text { n }\end{array}$} & \multirow{2}{*}{$\begin{array}{c}\text { Method to } \\
\text { detect } \\
C A L R \\
\text { mutations }\end{array}$} & \multirow[t]{2}{*}{ CALR mutation } & \multicolumn{3}{|c|}{$\begin{array}{l}\text { Frequency of } C A L R \text { and } J A K 2 \mathrm{~V} 617 \mathrm{~F} \text { co- } \\
\text { mutations }\end{array}$} \\
\hline & & & & In ET no. (\%) & $\begin{array}{c}\text { In } C A L R- \\
\text { mutated ET } \\
\text { no. }(\%)\end{array}$ & $\begin{array}{c}\text { In } \\
J A K 2 V 617 \mathrm{~F}- \\
\text { mutated ET } \\
\text { no. }(\%) \\
\end{array}$ \\
\hline $\begin{array}{l}\text { Lundberg et } \\
\text { al. [28] }\end{array}$ & Caucasian & $\begin{array}{l}\text { Allele- } \\
\text { specific } \\
\text { PCR }\end{array}$ & p.K385fs*47 & $1 / 69(1.4)$ & $1 / 17(5.9)$ & $1 / 41(2.4)$ \\
\hline $\begin{array}{l}\text { Fu et al. } \\
\text { [29] }\end{array}$ & Chinese & $\begin{array}{c}\text { Sanger } \\
\text { sequencing }\end{array}$ & $\begin{array}{l}\text { L367fs*46 } \\
\text { c. } 997 \mathrm{C}>\mathrm{T} \\
\text { (arginine }>\text { tryptophan) }\end{array}$ & $2 / 436(0.5)$ & $2 / 99(2)$ & $2 / 240(0.8)$ \\
\hline $\begin{array}{l}\text { Shirane et } \\
\text { al. }[30]\end{array}$ & Japanese & $\begin{array}{l}\text { Fragment } \\
\text { analysis } \\
\text { and deep } \\
\text { sequencing }\end{array}$ & p.E378fs $* 45$ & $1 / 111(0.9)$ & $1 / 22(4.5)$ & $1 / 60(1.7)$ \\
\hline $\begin{array}{l}\mathrm{Ha} \text { and } \mathrm{Kim} \\
{[31]}\end{array}$ & Korean & $\begin{array}{c}\text { Sanger } \\
\text { sequencing }\end{array}$ & p.L367fs*46 & $1 / 114(0.9)$ & $1 / 25(4)$ & $1 / 68(1.5)$ \\
\hline $\begin{array}{l}\text { Al Assaf et } \\
\text { al.[32] }\end{array}$ & Caucasian & $\begin{array}{c}\text { Sanger } \\
\text { sequencing }\end{array}$ & p.K385fs*47 & $1 / 160(0.6)$ & $1 / 59(1.7)$ & $1 / 57(1.8)$ \\
\hline $\begin{array}{l}\text { Lin et } \\
\text { al. }[33]\end{array}$ & Chinese & $\begin{array}{c}\text { Sanger } \\
\text { sequencing }\end{array}$ & $\begin{array}{l}2 \text { p.L367fs } * 46 \\
2 \text { p.K385fs } * 47\end{array}$ & $4 / 428(0.9)$ & $4 / 101(4.0)$ & $4 / 254(1.6)$ \\
\hline Lim et al. & Taiwanese & $\begin{array}{c}\text { HRMA } \\
\text { and } \\
\text { Sanger } \\
\text { sequencing }\end{array}$ & $\begin{array}{l}\text { p.L367fs*48 } \\
\text { p.E381A } \\
\text { p.K385fs*47 } \\
\text { p.E370fs*60 } \\
\text { p.E371fs*59 } \\
\text { p.E371del } \\
\text { p.E378del } \\
\text { p.E396del } \\
\text { p.E374X } \\
\text { p.E380X } \\
\text { p.K391X } \\
\text { p.E372G } \\
\text { p.E380G }\end{array}$ & $13 / 92(14.1)$ & $13 / 34(38)$ & $13 / 59(22)$ \\
\hline $\begin{array}{l}\text { Usseglio et } \\
\text { al. [35] }\end{array}$ & Caucasian & HRMA & $\begin{array}{l}2 \text { p.K385fs } * 47 \\
\text { p.L367fs } * 48 \\
\text { c. } 11251147 \mathrm{del}\end{array}$ & $4 / 103(3.9)$ & $4 / 48(8.3)$ & $4 / 56(7.1)$ \\
\hline $\begin{array}{l}\text { Lim et al. } \\
\text { (this study) }\end{array}$ & Taiwanese & $\begin{array}{c}\text { HRMA } \\
\text { and } \\
\text { Sanger } \\
\text { sequencing }\end{array}$ & $\begin{array}{l}\text { p.L367fs } * 48 \\
\text { p.E370fs } * 60 \\
\text { p.E371fs } * 59 \\
\text { p.E381del }\end{array}$ & $4 / 54(7.4)$ & $4 / 19(21.1)$ & $1 / 31(3.2)$ \\
\hline
\end{tabular}

Abbreviations: ET, essential thrombocythemia; HRMA, high-resolution melting analysis; no., number.

vast majority of the reports in the literature. The possible explanations for this discrepancy in our results might be related to small sample size and selection bias cannot be excluded completely in this study.

In accordance with our previous report, a relatively high frequency of CALR and JAK2V617F co-mutations (21\% in 19 CALR-mutated ET) was still found in this study. Several papers have reported the co-occurrence of
$C A L R$ and $J A K 2 \mathrm{~V} 617 \mathrm{~F}$ mutations in ET across different ethnic groups including one of our previous publication (Table 6). The frequency of CALR and JAK2V617F comutations ranges from 0.5 to $14.1 \%, 1.7$ to $38 \%$, and 0.8 to $22 \%$, in ET, CALR-mutated ET, and JAK2V617F-mutated ET, respectively [28-35]. The cause of the difference in the frequency of CALR and JAK2V617F co-mutations in these studies might be related to the different methods used to 
detect $C A L R$ mutations. Higher frequency of $C A L R$ and $J A K 2 \mathrm{~V} 617 \mathrm{~F}$ co-mutations was detected by using HRMA, whereas Sanger sequencing will likely miss to detect low allelic burden $(<10 \%) C A L R$ mutants. On the other hand, Usseglio et al. found that CALR mutations could be detected in low allelic burden $(<4 \%) J A K 2 \mathrm{~V} 617 \mathrm{~F}$ mutated ET suggesting that the frequency of $C A L R$ and $J A K 2 \mathrm{~V} 617 \mathrm{~F}$ co-mutations might be further increased if a highly sensitive test was employed to detect JAK2V617F mutation in CALR-mutated ET [35]. Since both of our studies used a sensitive in-house developed HRMA followed by TA-cloning to detected CALR mutations, we were able to identify many low allelic burden $C A L R$ mutants resulting in the higher frequency of $C A L R$ and $J A K 2 \mathrm{~V} 617 \mathrm{~F}$ co-mutations in our series. However, because our study was limited by small patient size, larger study using sensitive screening methods for the detection of both CALR and JAK2V617F mutations will be warranted to confirm our results.
Recently, we have shown that ET patients have quantitative and qualitative changes in their B cell immune profiles regardless of $J A K 2 \mathrm{~V} 617 \mathrm{~F}$ mutational status [23]. In our previous report, we found that the number of CD19+ $B$ cells did not differ between ET patients and age-matched healthy adults using univariate analysis. However, we found that ET patients had significantly lower numbers of total CD19+ B cells in univariate analysis (Table 2) and also in multivariate analysis adjusted for age, sex, followup period and hematological parameters (Table 4) in this study. We believe that the results reported in this study are more accurate because CALR-mutated ET patients were not included in our previous report and the results from multivariate analysis are more reliable. In the present study, we found that ET patients with CALR mutations also had similar quantitative and qualitative changes in most of the B cell immune profiles when compared to healthy adults using univariate and multivariate analyses (Tables 2 and 4, respectively). Although the number of
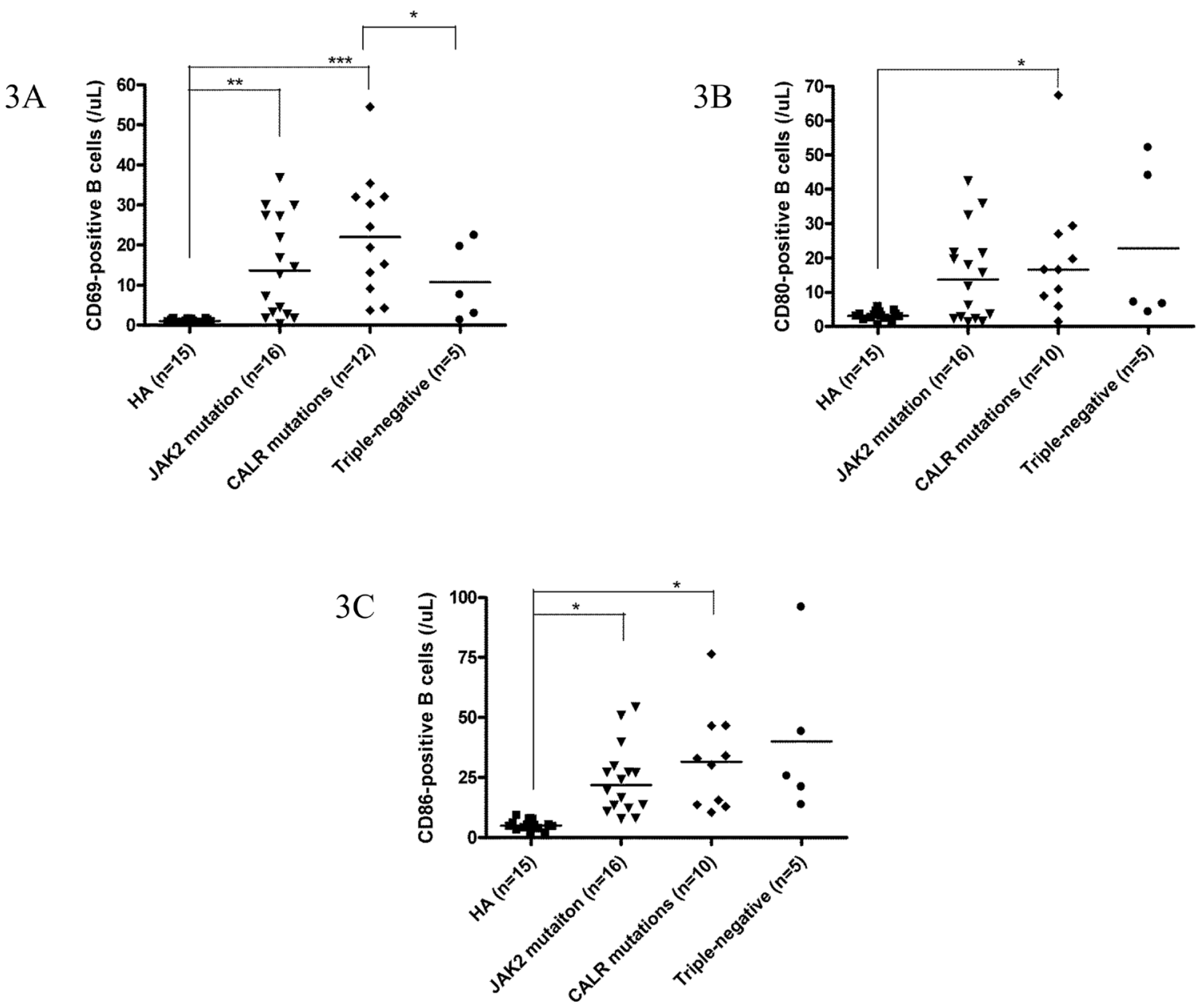

Figure 3: CALR mutations were associated with activated B cells in patients with ET. 3A, 3B and 3C, The number of activated B cells was higher in CALR-mutated ET patients, as evidenced by expression of CD69, CD80 and CD86, respectively. Data are presented as the number of B cells expressing these markers. Median values are indicated by the short horizontal bars. Asterisks represent significant differences between groups. $* p<0.05, * * p<0.01, * * * p<0.001$. 
total B cells was lower in ET patients including those with CALR mutations when compared with healthy controls, the number of activated B cells was significantly increased in ET patients across all 3 genotypes that characterized by the expression of CD69 and CD86, increased intracellular IL-6 and IL-1 $\beta$ levels, and higher expression of TLR4.

Regarding to the mechanism of $B$ cell activation in ET patients, it has been well documented that elevated serum levels of inflammatory cytokines are frequently detected in patients of MPN, especially PMF, and may correlate to their constitutional symptoms which could be effectively ameliorated by the use of JAK inhibitor [36]. Previous study has reported that cytokine levels were also significantly increased in ET and PV patients [37]. Therefore, it is reasonable to argue that $\mathrm{B}$ cell activation could only be an epiphenomenon in ET rather than a cause of thrombopoiesis. However, we found that increased B cell activation was only present in ET patients but not in PV patients when compared to healthy controls or patients with reactive thrombocytosis (Supplementary Table S2). Although we did not evaluate B cell immune profiles in PMF patients due to difficulty in patient enrollment, our findings provided evidence to illustrate that increased B cell activation in ET patients could not be solely explained by the increased cytokine levels in MPN patients, and therefore might not be an epiphenomenon in these patients. Nevertheless, we had previously reported that some humoral factors such as endogenous toll-like receptor 4 (TLR4) ligands HSP70 and HMGB1 or other inflammatory cytokines, might participate in the activation of B cells in ET patients because peripheral B cells of ET patients could be stimulated by ET patients' sera to cause IL-1beta and IL-6 production [23]. In addition, we had also demonstrated that increased production of BAFF by granulocytes and monocytes up-regulates TLR4 expression on B cells and promotes B cell activation in ET patients. Consequently, these activated B cells play a pathogenic role in augmenting thrombocytosis by producing IL- $1 \beta$ and IL-6 in ET patients through cytokinedependent thrombopoiesis in the bone marrow. Altogether, our data suggested that increased B cell activation in ET might be caused by the stimulation of specific humoral factors on B cells and the interaction of B cells with BAFF on granulocytes and monocytes. Importantly, our studies suggested that activated B cells in ET could play a role in mediating pathogenic thrombopoiesis in the bone marrow.

Besides, we had previously reported that TLR4 expression is upregulated in both naïve and memory $\mathrm{B}$ cell subsets, and BAFF receptor signaling has reciprocal effects on TLR interaction [23]. B cells are characterized by the expression of a clonally rearranged, antigenspecific B cell receptor (BCR) in combination with the expression of one or more members of the TLRs [38]. This dual expression feature allows B cells to integrate both antigen-specific signals and environmental danger signals via these key receptor systems. Since we did not measure or characterize the expression level of BCR on B cells, whether dual BCR and TLRs engagement may also play a role in the activation and/or affect the function of B cells in ET patients remains to be elucidated in future study.

Furthermore, we did not favor the paracrine effect of serum BAFF secreted by peripheral granulocytes and monocytes because its level was not different between ET patients and healthy controls in multivariate analysis. Rather, we hypothesized that the direct interaction between peripheral granulocytes and monocytes and B-cells might play a role in the activation of B-cells in ET patients since mBAFF expression was significantly higher in ET patients compared to healthy controls. Recently, mBAFF has been found to be a more potent stimulus for B cells than soluble BAFF thus supporting our view [39]. Our observation was also supported by the finding that mBAFF expression on peripheral granulocytes significantly correlated with higher number of IL-1 $\beta / \mathrm{IL}$ 6-producing B cells and activated B-cells in ET patients (Table 3). In addition, higher number of TLR4-producing $\mathrm{B}$ cells in JAK2-mutated and CALR-mutated ET patients might also augment the production of IL-1 $\beta /$ IL- 6 in B cells in these patients. We had previously shown that IL$1 \beta$ and IL-6 play an important role in thrombopoiesis in ET patients, and hematopoietic stem cells of ET patients differentiated towards a megakaryocytic lineage after incubation with their own B cells [23]. Therefore, our data suggested that activated B-cells in ET patients might link to the pathogenic thrombopoiesis in these patients through the production of IL-1 $\beta /$ IL- 6 in activated B cells regardless of their genotypes.

It is possible that the use cytoreductive therapy might affect B cell immune profiles in ET patients. However, most B cell immune profiles in ET patients were not affected by the treatment of hydroxyurea in this study (Supplementary Table S1). Therefore, we believed that the changes in B cell immune profiles may be more closely related to the underlying pathogenic mechanisms that could not be altered by non-specific cytoreductive therapy such as hydroxyurea.

Currently, the exact molecular mechanism of B cell activation in ET patients has not yet been fully elucidated. However, most of the changes in B cell immune profiles are independent of the three genotypes in ET patients, and the activation of JAK-STAT signaling pathway can be seen in most ET patients regardless of their molecular profiles [40]. JAK2V617F is a gain-of-function mutation resulting in the cytokine-independent growth of hematopoietic progenitors [41]. However, JAK2V617F mutation requires the presence of cytokine receptors (especially MPL) to be constitutively active [42]. JAK2V617F mutation can activate erythropoietin receptor, thrombopoietin receptor or granulocyte colony-stimulating factor receptor on progenitor cells to promote erythropoiesis, megakaryopoiesis, or granulopoiesis. Interestingly, $C A L R$ mutations are recently found to activate the JAK-STAT 
signaling through a MPL-dependent mechanism, and cause thrombocytosis both in vitro and in vivo. Hence, both $J A K 2 \mathrm{~V} 617 \mathrm{~F}$ and CALR mutations can activate the JAK-STAT signaling in megakaryocytes. Although CALR mutations can be detected in hematopoietic stem/ progenitor cells, it largely promotes the growth and the differentiation of megakaryocytic precursors resulting in the phenotype of ET and/or PMF. Therefore, CALR mutations are exclusively detected in around $25 \%$ of ET or PMF, but not in PV. On the other hand, JAK2V617F mutation can be identified in about $95 \%$ of PV and in around $60 \%$ of ET or PMF. Several observations have suggested that megakaryocytes play a major role in the pathogenesis of MPNs [43]. There is evidence suggesting that MPN associated mutations could alter megakaryocyte differentiation, migratory ability, and proplatelet formation, leading to increased platelet production [44]. $J A K 2 \mathrm{~V} 617 \mathrm{~F}$ mutation was also found to lead to intrinsic changes in both megakaryocyte and platelet biology in a mouse model of ET [45]. Recently, CALR mutations have been shown to activate essential MAPK signaling through MPL-dependent mechanism and facilitate megakaryocyte differentiation [46]. Current evidences suggest that both $J A K 2 \mathrm{~V} 617 \mathrm{~F}$ and $C A L R$ mutations intrinsically play a major role in the pathogenesis of ET through the promotion of megakaryopoiesis and thrombopoiesis. Based on our findings, increased platelet production in ET patients may be resulted from activating mutations synergistic with bystander thrombopoietic cytokines produced by activated $\mathrm{B}$ cells. We believe that these results would help advance our understanding of the pathogenesis of ET.

Our study is limited by a total number of 54 ET patients. However, the distribution and the percentage of the 3 driver mutations in these 54 ET patients were comparable with most studies: $27(50 \%)$ patients harbored the $J A K 2 \mathrm{~V} 617 \mathrm{~F}$ mutation, $1(1.9 \%)$ patient with the MPLW515K mutation, 19 (35.2\% overall and $68.2 \%$ in $J A K 2 / M P L$-unmutated cases) patients with $C A L R$ exon 9 mutations, and 7 (13\%) TN patients. In this study, we detected a higher percentage of $C A L R / J A K 2 \mathrm{~V} 617 \mathrm{~F}$ comutations in $4(7.4 \%)$ ET patients due to the use of a sensitive HRMA followed by TA-cloning to detect low allelic burden $C A L R$ mutants. To avoid statistic bias on the results, we excluded these $4 C A L R / J A K 2 \mathrm{~V} 617 \mathrm{~F}$ comutated ET patients and the only one $M P L$-mutated ET patient from further analysis. We have also consulted our bio-statistician for help with the analysis of our data. Our results showed that increased $\mathrm{B}$ cell activation is present in JAK2V617F-mutated, CALR-mutated and triplenegative ET, and these findings are consistent with our previous report. Although we believe that there was no statistical bias on the results, larger study is still warranted to confirm our findings. In conclusion, increased B cell activation is present in ET patients across different mutational subgroups.

\section{PATIENTS AND METHODS}

\section{Patient enrollment}

The screening for mutations in patients with hematologic neoplasms was approved by the Institutional Review Board of MacKay Memorial Hospital (09MMHIS157 and 12MMHIS034). 54 adult Taiwanese ET patients were enrolled and written informed consent was obtained. The clinical and laboratory characteristics at the time of diagnosis/referral and at testing were determined retrospectively by chart review. Parts of the clinical data of 48 patients in this cohort have been described in our recent publication [10].

\section{Mutation screening}

Genomic DNA derived from bone marrow granulocytes, peripheral blood leukocytes, peripheral blood granulocytes or peripheral blood mononuclear cells were used for the screening of $C A L R$ exon 9 mutations spanning codons 352-417 [GenBank: NM_004343]. Oligonucleotide primers targeting CALR exon 9 were used to amplify a 285 bp product: (CALR Forward 5'-CCTGCAGGCAGCAGAGAAAC-3') (CALR Reverse 5'-ACAGAGACATTATTTGGCGCG-3'). The PCR were amplified using GoTaq Green Master Mix (Promega, CA, USA) on a Thermal Cycler ${ }^{\circledR}$ PCR System 2720 (Applied Biosystems, CA, USA). The final concentrations were as follows: $3 \mathrm{mM} \mathrm{MgCl} 2$ and $0.4 \mathrm{mM}$ deoxyribo-nucleotide triphosphate, $2.5 \mu \mathrm{M}$ each of forward and reverse oligo primer, $50 \mathrm{ng}$ of DNA template and water to a final reaction volume of $20 \mu \mathrm{l}$. Cycling parameters consisted of an initial denaturation at $94^{\circ} \mathrm{C}$ for 5 min; 35 cycles of denaturation at $94^{\circ} \mathrm{C}$ for $30 \mathrm{~s}$, annealing at $58^{\circ} \mathrm{C}$ for $30 \mathrm{~s}$, and extension at $72^{\circ} \mathrm{C}$ for $45 \mathrm{~s}$; and final extension at $72^{\circ} \mathrm{C}$ for $10 \mathrm{~min}$. The EXO-SAP reagent (USB, CA, USA) was used to clean up the PCR product prior to sequencing. Direct DNA sequencing was conducted using the same primers for amplification and a BigDye terminator v3.1 Cycle sequencing kit (Applied Biosystems, CA, USA) on an ABI 3730 sequencer. Mutations were identified using DNA Dynamo sequence analysis software (Blue Tractor Software Ltd, Conwy, UK). All identified sequence variants were subjected to repeated bidirectional sequencing for confirmation. CALR exon 9 mutations were also independently screened by high-resolution melting analysis (HRMA) and TA-cloning was used to detected low allelic burden mutants in selected samples as previously described [47]. JAK2V617F mutation was determined by allele-specific PCR as previously described and/or mutation-enrich high sensitive PCR method over $J A K 2$ exon 14 mutation hot spot area $[48,49]$. $M P L$ exon 10 mutation was screened by nucleotide sequencing 
as previously described [50]. In order to exclude the influence of other possible mutations on B cell immune profiles, DNMT3A exon 23 and $I D H 1 / 2$ exon 4 mutations were also screened as previously described [50].

\section{B cell immune profiles}

The quantification of $\mathrm{B}$ cell populations and various B cell subsets including T1, T2, pre-germinal center, memory, and plasmablast/plasma cells, based upon the surface expression of CD19, CD24, CD27, CD38, and IgD was assessed by flow cytometric analysis as previously described [23]. Granulocytes and monocytes membranebound BAFF (mBAFF) levels, TLR4 expression and intracellular levels of IL-1 $\beta / \mathrm{IL}-6$ and the expression of CD69, CD80, and CD86 on B cells were quantified by flow cytometry using appropriated antibodies [23]. Serum BAFF concentration was measured by ELISA kit from R\&D Systems according to the manufacturer's instructions. The B cell immune profiles of 38 patients in this cohort had been described in our previous publication [23]. B cell immune profiles from 48 healthy adults were used for comparison.

\section{Statistical analysis}

The correlation between $C A L R$ mutational status and clinical characteristics was calculated by the chisquare test or Fisher's exact test. Kolmogorov-Smirnov test was used to test normality of numerical variables. The independent $t$-test and the one-way analysis of variance (ANOVA) were used to compare differences between two and three independent groups when the dependent variables were normally distributed, respectively. When the dependent variables were not normally distributed, non-parametric Mann-Whitney U test and Kruskal-Wallis $\mathrm{H}$ test were used to compare differences between two and three independent groups, respectively. Spearman's rank correlation coefficient was used to evaluate the relationship between two variables. Multivariate analysis was performed using linear regression model adjusted for age, sex, follow-up period and hematological parameters. Statistical significance was defined as a two-sided $p$ value $<0.05$ and SPSS version 22.0 (IBM, New York, USA) was used for analyses.

\section{ACKNOWLEDGMENTS}

We are grateful to Drs. Kuei-Fang Chou, Po-Nien Liao and Guan-Jhe Cai for their help in patient enrollment. We thank Dr. Wen-Chien Chou for critical reading and editing the manuscript. We are grateful to our statistician Mrs. Fang-Ju Sun for the help with statistical analysis.

\section{CONFLICTS OF INTEREST}

The authors declare no conflict of interest.

\section{GRANT SUPPORT}

This study was supported by grants from the Ministry of Science and Technology of Taiwan to KHL (grant numbers: MOST 102-2314-B-195-015-MY2 and MOST 104-2314-B-195-017-MY3) and YYK (grant number: MOST 103-2314-B-002-168 and MOST 105-2314-B-002-185-MY2), and the intramural grants from the Department of Medical Research of MacKay Memorial Hospital to KHL and HCL. The funders had no role in study design, data collection and analysis, decision to publish, or preparation of the manuscript.

\section{Editorial note}

This paper has been accepted based in part on peerreview conducted by another journal and the authors' response and revisions as well as expedited peer-review in Oncotarget.

\section{REFERENCES}

1. Tefferi A, Vainchenker W. Myeloproliferative neoplasms: molecular pathophysiology, essential clinical understanding, and treatment strategies. J Clin Oncol. 2011; 29: 573-582.

2. James C, Ugo V, Le Couedic JP, Staerk J, Delhommeau F, Lacout C, Garcon L, Raslova H, Berger R, BennaceurGriscelli A, Villeval JL, Constantinescu SN, Casadevall N, et al. A unique clonal JAK2 mutation leading to constitutive signalling causes polycythaemia vera. Nature. 2005; 434: 1144-1148.

3. Baxter EJ, Scott LM, Campbell PJ, East C, Fourouclas N, Swanton S, Vassiliou GS, Bench AJ, Boyd EM, Curtin N, Scott MA, Erber WN, Green AR, et al. Acquired mutation of the tyrosine kinase JAK2 in human myeloproliferative disorders. Lancet. 2005; 365: 1054-1061.

4. Kralovics R, Passamonti F, Buser AS, Teo SS, Tiedt R, Passweg JR, Tichelli A, Cazzola M, Skoda RC. A gain-offunction mutation of JAK2 in myeloproliferative disorders. N Engl J Med. 2005; 352: 1779-1790.

5. Levine RL, Wadleigh M, Cools J, Ebert BL, Wernig G, Huntly BJ, Boggon TJ, Wlodarska I, Clark JJ, Moore S, Adelsperger J, Koo S, Lee JC, et al. Activating mutation in the tyrosine kinase JAK2 in polycythemia vera, essential thrombocythemia, and myeloid metaplasia with myelofibrosis. Cancer Cell. 2005; 7: 387-397.

6. Lu X, Levine R, Tong W, Wernig G, Pikman Y, Zarnegar S, Gilliland DG, Lodish H. Expression of a homodimeric type I cytokine receptor is required for JAK2V617F-mediated transformation. Proc Natl Acad Sci U S A. 2005; 102: 
18962-18967.

7. Klampfl T, Gisslinger H, Harutyunyan AS, Nivarthi H, Rumi E, Milosevic JD, Them NC, Berg T, Gisslinger B, Pietra D, Chen D, Vladimer GI, Bagienski K, et al. Somatic mutations of calreticulin in myeloproliferative neoplasms. N Engl J Med. 2013; 369: 2379-2390.

8. Nangalia J, Massie CE, Baxter EJ, Nice FL, Gundem G, Wedge DC, Avezov E, Li J, Kollmann K, Kent DG, Aziz A, Godfrey AL, Hinton J, et al. Somatic CALR mutations in myeloproliferative neoplasms with nonmutated JAK2. N Engl J Med. 2013; 369: 2391-2405.

9. Lim KH, Lin HC, Gon-Shen Chen C, Chiang YH, Hsiao CD, Kuo YY. CALR mutations in myeloproliferative neoplasms. Int J Gerontol. 2014; 8: 105.

10. Lim KH, Chang YC, Gon-Shen Chen C, Lin HC, Wang WT, Chiang YH, Cheng HI, Su NW, Lin J, Chang YF, Chang MC, Hsieh RK, Kuo YY, et al. Frequent CALR exon 9 alterations in JAK2 V617F-mutated essential thrombocythemia detected by high-resolution melting analysis. Blood Cancer J. 2015; 5: e295.

11. Rotunno G, Mannarelli C, Guglielmelli P, Pacilli A, Pancrazzi A, Pieri L, Fanelli T, Bosi A, Vannucchi AM, Associazione Italiana per la Ricerca sul Cancro Gruppo Italiano Malattie Mieloproliferative I. Impact of calreticulin mutations on clinical and hematological phenotype and outcome in essential thrombocythemia. Blood. 2014; 123: 1552-1555.

12. Lim KH, Chang YC, Chiang YH, Lin HC, Chang CY, Lin CS, Huang L, Wang WT, Gon-Shen Chen C, Chou WC, Kuo YY. Expression of CALR mutants causes mpldependent thrombocytosis in zebrafish. Blood Cancer J. 2016; 6: e481.

13. Marty C, Pecquet C, Nivarthi H, El-Khoury M, Chachoua I, Tulliez M, Villeval JL, Raslova H, Kralovics R, Constantinescu SN, Plo I, Vainchenker W. Calreticulin mutants in mice induce an MPL-dependent thrombocytosis with frequent progression to myelofibrosis. Blood. 2016; 127: 1317-1324.

14. Nivarthi H, Chen D, Cleary C, Kubesova B, Jager R, Bogner E, Marty C, Pecquet C, Vainchenker W, Constantinescu $\mathrm{SN}$, Kralovics R. Thrombopoietin receptor is required for the oncogenic function of CALR mutants. Leukemia. 2016; 30: 1759-1763.

15. Shide K, Kameda T, Yamaji T, Sekine M, Inada N, Kamiunten A, Akizuki K, Nakamura K, Hidaka T, Kubuki Y, Shimoda H, Kitanaka A, Honda A, et al. Calreticulin mutant mice develop essential thrombocythemia that is ameliorated by the JAK inhibitor ruxolitinib. Leukemia. 2016 Nov 29. [Epub ahead of print].

16. Chachoua I, Pecquet C, El-Khoury M, Nivarthi H, Albu RI, Marty C, Gryshkova V, Defour JP, Vertenoeil G, Ngo A, Koay A, Raslova H, Courtoy PJ, et al. Thrombopoietin receptor activation by myeloproliferative neoplasm associated calreticulin mutants. Blood. 2016; 127: 13251335.
17. Araki M, Yang Y, Masubuchi N, Hironaka Y, Takei H, Morishita S, Mizukami Y, Kan S, Shirane S, Edahiro Y, Sunami Y, Ohsaka A, Komatsu N. Activation of the thrombopoietin receptor by mutant calreticulin in CALRmutant myeloproliferative neoplasms. Blood. 2016; 127 : 1307-1316.

18. Elf S, Abdelfattah NS, Chen E, Perales-Paton J, Rosen EA, Ko A, Peisker F, Florescu N, Giannini S, Wolach O, Morgan EA, Tothova Z, Losman JA, et al. Mutant Calreticulin Requires Both Its Mutant C-terminus and the Thrombopoietin Receptor for Oncogenic Transformation. Cancer Discov. 2016; 6: 368-381.

19. Gold LI, Eggleton P, Sweetwyne MT, Van Duyn LB, Greives MR, Naylor SM, Michalak M, Murphy-Ullrich JE. Calreticulin: non-endoplasmic reticulum functions in physiology and disease. FASEB J. 2010; 24: 665-683.

20. Tesniere A, Apetoh L, Ghiringhelli F, Joza N, Panaretakis T, Kepp O, Schlemmer F, Zitvogel L, Kroemer G. Immunogenic cancer cell death: a key-lock paradigm. Curr Opin Immunol. 2008; 20: 504-511.

21. Zhang T, Xia Y, Zhang L, Bao W, Hong C, Gao XM. CD1d(hi)CD5(+) B cells differentiate into antibodysecreting cells under the stimulation with calreticulin fragment. Protein Cell. 2013; 4: 872-881.

22. Hong $\mathrm{C}$, Zhang $\mathrm{T}$, Gao XM. Recombinant murine calreticulin fragment 39-272 expands CD1d(hi)CD5+ IL-10-secreting $B$ cells that modulate experimental autoimmune encephalomyelitis in C57BL/6 mice. Mol Immunol. 2013; 55: 237-246.

23. Liu CC, Wang SC, Kao CW, Hsieh RK, Chang MC, Chang YF, Lim KH, Chen CG. B cells facilitate platelet production mediated by cytokines in patients with essential thrombocythaemia. Thromb Haemost. 2014; 112: 537-550.

24. Wu Z, Zhang X, Xu X, Chen Y, Hu T, Kang Z, Li S, Wang H, Liu W, Ma X, Guan M. The mutation profile of JAK2 and CALR in Chinese Han patients with Philadelphia chromosome-negative myeloproliferative neoplasms. J Hematol Oncol. 2014; 7: 48.

25. Tefferi A, Wassie EA, Guglielmelli P, Gangat N, Belachew AA, Lasho TL, Finke C, Ketterling RP, Hanson CA, Pardanani A, Wolanskyj AP, Maffioli M, Casalone R, et al. Type 1 versus Type 2 calreticulin mutations in essential thrombocythemia: a collaborative study of 1027 patients. Am J Hematol. 2014; 89: E121-124.

26. Chen CC, Gau JP, Chou HJ, You JY, Huang CE, Chen YY, Lung J, Chou YS, Leu YW, Lu CH, Lee KD, Tsai YH. Frequencies, clinical characteristics, and outcome of somatic CALR mutations in JAK2-unmutated essential thrombocythemia. Ann Hematol. 2014; 93:2029-36.

27. Tefferi A, Wassie EA, Lasho TL, Finke C, Belachew AA, Ketterling RP, Hanson CA, Pardanani A, Gangat N, Wolanskyj AP. Calreticulin mutations and long-term survival in essential thrombocythemia. Leukemia. 2014; 28: $2300-2303$. 
28. Lundberg P, Karow A, Nienhold R, Looser R, HaoShen H, Nissen I, Girsberger S, Lehmann T, Passweg J, Stern M, Beisel C, Kralovics R, Skoda RC. Clonal evolution and clinical correlates of somatic mutations in myeloproliferative neoplasms. Blood. 2014; 123: 22202228.

29. Fu R, Xuan M, Zhou Y, Sun T, Bai J, Cao Z, Zhang L, Li H, Zhang D, Zhang X, Lv C, Xue F, Liu X, et al. Analysis of calreticulin mutations in Chinese patients with essential thrombocythemia: clinical implications in diagnosis, prognosis and treatment. Leukemia. 2014; 28: 1912-1914.

30. Shirane S, Araki M, Morishita S, Edahiro Y, Takei H, Yoo Y, Choi M, Sunami Y, Hironaka Y, Noguchi M, Koike M, Noda N, Ohsaka A, et al. JAK2, CALR, and MPL mutation spectrum in Japanese patients with myeloproliferative neoplasms. Haematologica. 2015; 100: e46-48.

31. Ha JS, Kim YK. Calreticulin exon 9 mutations in myeloproliferative neoplasms. Ann Lab Med. 2015; 35: 22-27.

32. Al Assaf C, Van Obbergh F, Billiet J, Lierman E, Devos T, Graux C, Hervent AS, Emmerechts J, Tousseyn T, De Paepe P, Papadopoulos P, Michaux L, Vandenberghe P. Analysis of phenotype and outcome in essential thrombocythemia with CALR or JAK2 mutations. Haematologica. 2015; 100: 893-897.

33. Lin Y, Liu E, Sun Q, Ma J, Li Q, Cao Z, Wang J, Jia Y, Zhang H, Song Z, Ai X, Shi L, Feng X, et al. The Prevalence of JAK2, MPL, and CALR Mutations in Chinese Patients With BCR-ABL1-Negative Myeloproliferative Neoplasms. Am J Clin Pathol. 2015; 144: 165-171.

34. Lim KH, Chang YC, Chen CG, Lin HC, Wang WT, Chiang YH, Cheng HI, Su NW, Lin J, Chang YF, Chang MC, Hsieh RK, Kuo YY, et al. Frequent CALR exon 9 alterations in JAK2 V617F-mutated essential thrombocythemia detected by high-resolution melting analysis. Blood Cancer J. 2015; 5: e295.

35. Usseglio F, Beaufils N, Calleja A, Raynaud S, Gabert J. Detection of CALR and MPL Mutations in Low Allelic Burden JAK2 V617F Essential Thrombocythemia. J Mol Diagn. 2017; 19: 92-98.

36. Verstovsek S, Kantarjian H, Mesa RA, Pardanani AD, Cortes-Franco J, Thomas DA, Estrov Z, Fridman JS, Bradley EC, Erickson-Viitanen S, Vaddi K, Levy R, Tefferi A. Safety and efficacy of INCB018424, a JAK1 and JAK2 inhibitor, in myelofibrosis. N Engl J Med. 2010; 363: 1117 1127.

37. Pourcelot E, Trocme C, Mondet J, Bailly S, Toussaint B, Mossuz P. Cytokine profiles in polycythemia vera and essential thrombocythemia patients: clinical implications. Exp Hematol. 2014; 42: 360-368.

38. Rawlings DJ, Schwartz MA, Jackson SW, Meyer-Bahlburg A. Integration of B cell responses through Toll-like receptors and antigen receptors. Nat Rev Immunol. 2012; 12: $282-294$.
39. Manetta J, Bina H, Ryan P, Fox N, Witcher DR, Kikly K. Generation and characterization of tabalumab, a human monoclonal antibody that neutralizes both soluble and membrane-bound B-cell activating factor. J Inflamm Res. 2014; 7: 121-131.

40. Rampal R, Al-Shahrour F, Abdel-Wahab O, Patel JP, Brunel JP, Mermel CH, Bass AJ, Pretz J, Ahn J, Hricik T, Kilpivaara O, Wadleigh M, Busque L, et al. Integrated genomic analysis illustrates the central role of JAKSTAT pathway activation in myeloproliferative neoplasm pathogenesis. Blood. 2014; 123: e123-133.

41. Cahu X, Constantinescu SN. Oncogenic Drivers in Myeloproliferative Neoplasms: From JAK2 to Calreticulin Mutations. Curr Hematol Malig Rep. 2015; 10: 335-343.

42. Sangkhae V, Etheridge SL, Kaushansky K, Hitchcock IS. The thrombopoietin receptor, MPL, is critical for development of a JAK2V617F-induced myeloproliferative neoplasm. Blood. 2014; 124: 3956-3963.

43. Papadantonakis N, Matsuura S, Ravid K. Megakaryocyte pathology and bone marrow fibrosis: the lysyl oxidase connection. Blood. 2012; 120: 1774-1781.

44. Balduini A, Badalucco S, Pugliano MT, Baev D, De Silvestri A, Cattaneo M, Rosti V, Barosi G. In vitro megakaryocyte differentiation and proplatelet formation in $\mathrm{Ph}$-negative classical myeloproliferative neoplasms: distinct patterns in the different clinical phenotypes. PLoS One. 2011; 6: e21015.

45. Hobbs CM, Manning H, Bennett C, Vasquez L, Severin S, Brain L, Mazharian A, Guerrero JA, Li J, Soranzo N, Green AR, Watson SP, Ghevaert C. JAK2V617F leads to intrinsic changes in platelet formation and reactivity in a knock-in mouse model of essential thrombocythemia. Blood. 2013; 122: 3787-3797.

46. Kollmann K, Warsch W, Gonzalez-Arias C, Nice FL, Avezov E, Milburn J, Li J, Dimitropoulou D, Biddie S, Wang M, Poynton E, Colzani M, Tijssen MR, et al. A novel signalling screen demonstrates that CALR mutations activate essential MAPK signalling and facilitate megakaryocyte differentiation. Leukemia. 2017 in press.

47. Lim KH, Lin HC, Chen CG, Wang WT, Chang YC, Chiang YH, Lin CS, Su NW, Su YW, Lin J, Chang YF, Chang MC, Hsieh RK, et al. Rapid and sensitive detection of CALR exon 9 mutations using high-resolution melting analysis. Clin Chim Acta. 2015; 440: 133-139.

48. Lin HC, Chen CG, Chang MC, Wang WT, Kao CW, Lo AC, Su NW, Chang YC, Chiang YH, Chou KF, Liao PN, Cai GJ, Cheng HI, et al. JAK2 V617F mutation in adult Taiwanese patients with essential thrombocythemia: more prevalent in old patients and correlated with higher hemoglobin level and higher leukocyte count. Int J Gerontol. 2013; 7: 40-44.

49. Li S, Kralovics R, De Libero G, Theocharides A, Gisslinger $\mathrm{H}$, Skoda RC. Clonal heterogeneity in polycythemia vera patients with JAK2 exon12 and JAK2-V617F mutations. Blood. 2008; 111: 3863-3866. 
50. Lin HC, Wang SC, Chen CG, Chang MC, Wang WT, Su NW, Cheng HI, Lin J, Chang YF, Hsieh RK, Chang $\mathrm{CC}$, Hwang Y, Lim $\mathrm{KH}$, et al. Mutation and lineage analysis of DNMT3A in BCR-ABL1-negative chronic myeloproliferative neoplasms. Int J Gerontol. 2013; 7: 186188. 